JEECOM, Vol. 2, No. 2, Oktober 2020

\title{
KONTROL SISTEM STARTER SEPEDA MOTOR BERBASIS MIKROKONTROLER DENGAN SMARTPHONE ANDROID MENGGUNAKAN VOICE RECOGNITION
}

\author{
Abdul Rosyid ${ }^{1)}$, Agus Setia Budi ${ }^{2)}$, Purnomo Hadi Susilo ${ }^{3)}$ \\ ${ }^{1,2,3)}$ Mahasiswa Program Studi Teknik Informatika, Fakultas Teknik, Universitas Islam Lamongan \\ Jl. Veteran No. 53 A Lamongan, Jawa Timur, Indonesia \\ Telp. (0332)324706 \\ E-Mail :rosyida623@gmail.com ${ }^{1}$,geniusbudi@unisla.ac.id ${ }^{2}$,purnomo@unisla.ac.id $^{3}$
}

\begin{abstract}
ABSTRAK
Penelitian ini bertujuan untuk keamanan dan efektifitasan dalam pemakaian kendaraan roda dua atau sepeda motor yang menggunakan smarthphone. Dalam keamanan dan kemudahan pemakai dalam menggunakan kendaraan roda dua tanpa menggunakan kunci konvensional. Selama ini, karena maraknya kasus pencurian motor yang sering terjadi. Sehingga pemakaian merasa resah akan kasus tersebut. Maka penelitian ini dibuat untuk membantu pemakai kendaraan roda dua dalam keamanan kendaraan. Hasil penelitian ini menunjukan bahwa tanpa menggunakan kunci konvensional masih bias untuk menyala. Sistem kemanan ini berbasis relai dan akan dikendalikan melalui smartphone dengan sistem operasi Android. Sistem komunikasi dirancang dengan menggunakan modul bluetooth HC-06 yang dapat diintegrasikan dengan papan mikrokontroler Arduino Uno. Detail perancangan sistem dijelaskan pada skripsi ini. Hasil pengujian menunjukan jarak maksimal komunikasi bluetooth antara pengendali (smartphone) dengan sistem pada sepeda motor yaitu $10 \mathrm{M}$.
\end{abstract}

Kata kunci : Arduino Uno, Smartphone, Bluetooth HC-06

\begin{abstract}
This study aims to safety and effectiveness in the use of two-wheeled vehicles or motorbikes using smartphones. In the safety and ease of users in using two-wheeled vehicles without using conventional keys. During this time, because of the rampant cases of motorcycle theft that often occurs. So that the use feel uneasy about the case. So this research was made to help two-wheeled vehicle users in vehicle safety. The results of this study indicate that without using a conventional key is still biased to ignite. This security system is relay based and will be controlled via a smartphone with the Android operating system. The communication system is designed using the HC-06 bluetooth module which can be integrated with the Arduino Uno microcontroller board. System design details are explained in this thesis. The test results show the maximum distance of bluetooth communication between the controller (smartphone) with the system on a motorcycle that is $10 \mathrm{M}$.
\end{abstract}

Keywords: Arduino Uno, Smartphone, Bluetooth HC-06 


\section{PENDAHULUAN}

Mulai semakin majunya era globalisasi yang terus menerus meningkat, yang akhirnya berdampak pada semakin berkembangnya alatalat elektronik yang pengoprasianya berbasis teknologi yang akhirnya berdampak positif dengan semakin memudahkan manusia untuk melakukan aneka variasi kegiatan dengan sangat mudah. dengan dibuktikanya semakin banyak munculnya berbagai macam robot yang kemudian di aplikasikan dengan berbagai teknologi. Seiring perkembangan teknologi elektronik, yang salah satunya mikrokontroler dan juga sensor yang murah memberikan kemudahan dalam pemrogramanya seperti arduino. Peneliti atau pembuat jadi lebih gampang dan juga akan lebih efektif dalam merangkai alat Jika pada abad-abad terdahulu tidak mudah untuk membuat sebuah alat berbasis intellegensi karena tidak adanya alat dan susahnya memprogram alat tersebut. adanya Mikrokontroler Arduino dan juga sensor sidik jari adalah design sistem minimum mikrokontroler dengan modul mikrokontroler AVR, sehingga dapat dijalankan untuk membangun sistem elektronika berukuran minimalis dan tetap handal dan juga cepat.

Teknologi akses menghidupkan sepeda motor mengalami perkembangan yang awalnya menggunakan metode konvensional atau manual menggunakan engkol atau terlebih dahulu dengan kunci kontak, sekarang mengalami perkembangan yaitu dengan password atau sidik jari. Akses pada suatu kendaraan bermotor roda dua yang sangat rahasisa atau motor khusus yang tidak sembarang orang bisa akses ke kendaraan motor tersebut. sistem ini akan mengatasi seringnya terjadi kehilangan kunci motor yang biasannya digunakan untuk menghidupkan mesin kendaraan bermotor.

Hal yang sama sering terjadi ketika kita hendak berangkat kerja atau hendak beraktifitas seringkali lupa menaruh kunci kendaraan, maka berapa waktu yang akan dialokasikan jika kunci motor belum ditemukan. Sehingga dengan adanya sistem ini akan memangkas waktu yang seharusnya digunakan untuk menyelesaikan pekerjaan manusia.

Teknologi smartphone dengan sistem voice recognition yang dikoneksikan dengan Arduino
UNO ATmega328 bisa dikoneksikan dengan peralatan elektronika bahkan dengan peralatan yang lebih besar dan voltse lebih besar melalui relay dengan mekanisme tertentu. Cukup mengontrol dengan smartphone ini maka sistem akan merespon dan mesin kendaraan bermotor kita akan secara otomatis hidup.

\section{METODOLOGI PENELITIAN}

Metodologi merupakan metode pengumpulan data atau suatu cara mendapatkan data-data yang dibutuhkan dalam menyelesaikan tugas akhir ini. Adapun metode yang digunakan adalah sebagai berikut:

1. Analisa kebutuhan

Tahapan ini merupakan analisa terhadap kebutuhan sistem. Pengumpulan datadata serta referensi yang akan membantu merancangsistem.

2. Desain Sistem

Tahapan ini merupakan penuangan pikiran dan perancangan sistem yang akan dibuat dengan tujuan sebelum melakukan coding dapat memudahkan penulis dalam menentukan cara kerja sistem dan tampilanaplikasi.

3. Penulisan Kode Program

Pembuatan aplikasi akan dibuat dengan menggunakan aplikasi android Studio yang merupakan layanan untuk menciptakan aplikasi perangkat lunak bagi sistem operasiAndroid.

4. Pengujian Program

Tahapan ini dilakukan untuk mengetahui kemampuan dan keefektifan serta mengetahui apakah sistem tersebut layak untukditerapkan.

5. Penerapan program

Tahapan ini dilakukan untuk menyatukan tahapan- tahapan yang telah dirancang menjadi satu.

\section{Skema Alur Program}

Skema alur program ini yaitu kode perintah Android diterima melalui Bluetooth HC-06, Arduino Uno akan menerima data dari Android dan menerjemahkanya untuk menghidupkan dan mematikan motor dengan metode voice recognition, sehingga starter sepeda motor dapat dikendalikan dengan Android Smartphone dari jarak jauh. 


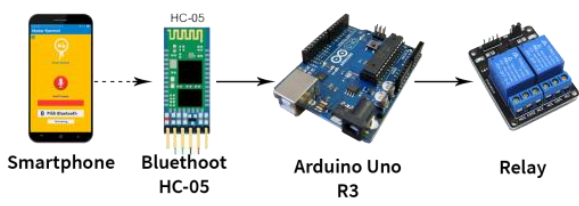

Gambar 1 Skema Alur Program

\section{Flowcarth Alur Sistem}

Alur sistem program penelitian ini dilakukan dengan beberapa tahapan, skema alur sistem penelitian dijelaskan pada Gambar 3.4 sebagai berikut.

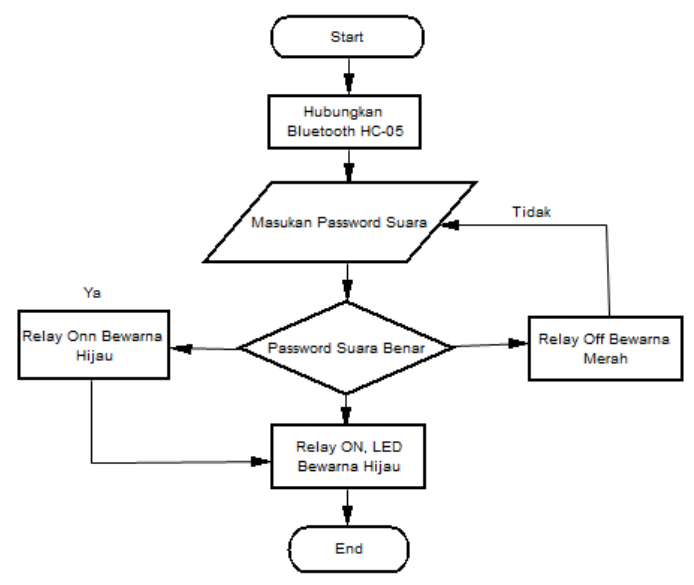

Gambar 2 Flowchart.

Dari flowchart pada Gambar 3.4 dapat dijelaskan bagaimana cara fungsi alat tersebut, cara penggunaannya harus menghubungkan terlebih dahulu bluethoot antara aplikasi smartphone android dengan mikrokontroler Arduino uno ATMega328, setelah bluethoot terkoneksi maka selanjutnya memasukan password suara yang sebelumnya sudah terprogram dalam mikrokontroler Arduino uno dan Apabila suara password yang telah terdaftar dalam program maka mikrokontroler Arduino uno ATMega328 akan memberi perintah untuk mengaktifkan starter kendaraan. Apabila password suara tidak dikenali tersebut belum terdaftar, maka mikrokontroler Arduino uno ATMega328 tidak akan memberi perintah dan sepedah motor tidak akan hidup.

\section{IMPLEMENTASI}

Implementasi merupakan penjabaran atau suatu pelaksanaan terhadap struktur perencanaan yang telah dilakukan sebelumnya. Implementasi memungkinkan tiap programmer untuk melakukan uji coba sistem yang sebelumnya telah dirancang melalui sejumlah mekanisme yang ada. Tak hanya itu, implementasi juga bertujuan untuk mengetahui apakah perancangan yang sudah dilakukan dari awal hingga akhir sudah tidak terdapat masalah yang ditemui.

Pada tahap implementasi rancangan halaman yang telah dibuat kemudian diaplikasikan dengan menggunakan bahasa pemograman php. Hasil implementasi dari perancangan yang telah dibuat antara lain sebagai berikut :

1. Halaman Login Aplikasi

Pada halaman login user dapat melakukan login dengan memasukkan username dan password yang nantinya akan digunakan untuk masuk ke menu utama aplikasi jika username dan password yang dimasukan benar maka akan secara otomatis masuk pada menu halaman utama aplikasi.

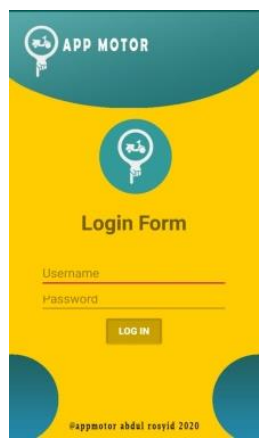

\section{Gambar 3 Halaman Login}

2. Halaman Menu Utama Aplikasi

Pada menu ini terdapat Menu Utama, dan di menu utama setelah melakukan login maka akan masuk ke menu utama dari aplikasi ini dan menu dari aplikasi ini yang dimana ada Menu Kontrol atau voice ini adalah digunakan untuk mengontrol atau menghidupkan kendaraan, Menu Tutorial ini digunakan untuk mengetahui cara penggunaan dari aplikasi dan Menu Tentang aplikasi adalah untuk mengetahui profil dari aplikasi. 


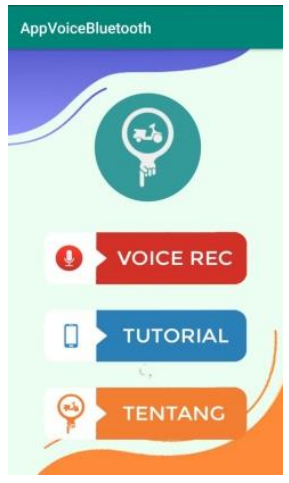

\section{Gambar 4 Halaman Menu Utama}

3. Halaman Menu Kontrol

Pada menu kontrol dibuka aplikasi otomatis mengecek apakah bluetooth sudah aktif atau belum, apabila belum akan muncul notifikasi untuk mengaktifkan bluetooth melalui aplikasi pengaman. Apabila sudah aktif lalu tekan tombol "setting" dan pilih bluetooth mana yang akan disambungkan dengan android.

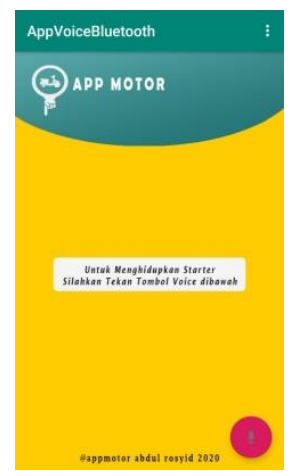

\section{Gambar 4 Halaman Menu Kontrol}

4. Halaman Menu Setting

Menu Setting Bluetooth untuk mengkoneksikan antara aplikasi dan juga hardware. Pada menu setting ini sebelumnya perangkat Bluetooth di Android harus terlebih dahulu disandingkan sesuai dengan nama Bluetooth yang ada pada hardware setelah sama maka bluetooth baru bisa terhubung dengan hardware. Setelah terhubung selanjutnya baru masuk dan tekan tombol voice untuk memasukan inputan suara sesuai dengan program yang dimasukan pada hardware. Jika Bluetooth tidak dinyalakan atau tidak dihubungkan maka aplikasi tidak akan bisa memerintahkan hardware, meskipun dengan kita menekan atau menginputkan suara sesuai dengan password yang kita masukan dalam program aplikasi. Dan untuk jarak Bluetooth antara aplikasi dan hardware adalah sejauh $10 \mathrm{M}$. jika melebihi jarak $10 \mathrm{M}$ maka sambungan Bluetooth antara hardware dan aplikasi akan terputus secara otomatis.

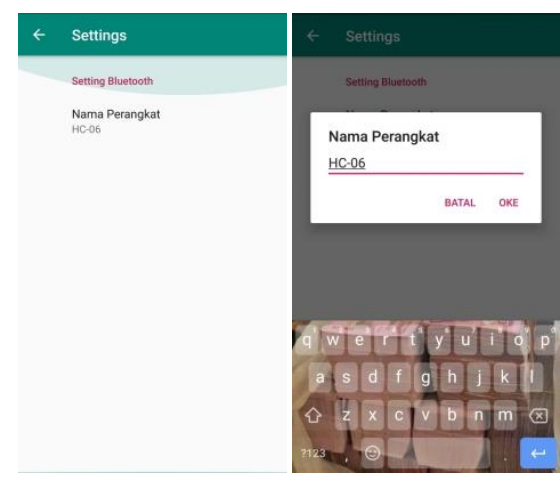

\section{Gambar 4 Halaman Menu Setting}

5. Menu Tutorial Aplikasi

Pada halaman tutorial adalah untuk mengetahui langkah - langkah penggunaan aplikasi.

a. Dalam menu tutorial dijelaskan bagaimana cara untuk menghidupkan Bluetooth agar aplikasi bisa tersambung dengan hardware,

b. Bagaimana memasukan suara ke aplikasi agar aplikasi mampu mengontrol hardware.

c. Suara mampu dikenali dan sesuai database password yang dimasukan dalam program

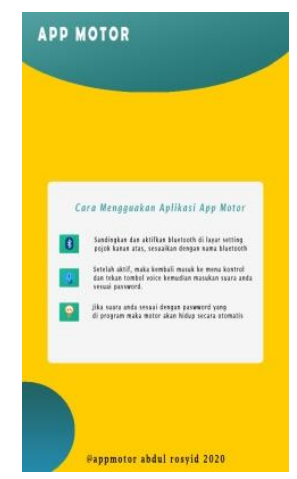

Gambar 5 Menu Tutorial Aplikasi 
6. Menu Tentang Aplikasi

Pada menu tentang aplikasi adalah untuk mengetahui profil daripada aplikasi yang digunakan.

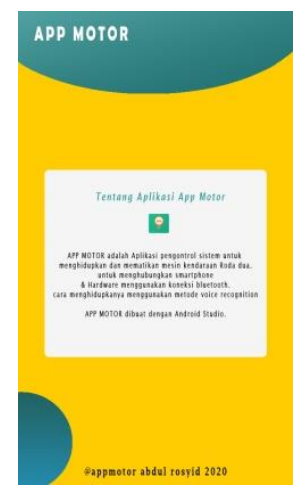

Gambar 6 Menu Tentang Aplikasi

\section{Pengujian Sistem}

Setelah sistem selesai dibuat, maka perlu dilakukan pengujian terhadap sistem tersebut. Pengujian sistem ini bertujuan untuk mengetahui sejauh mana sistem dapat memenuhi kebutuhan user dan sejauh mana kecepatan eksekusi yang dilakukan oleh sistem. Pengujian sistem ini dilakukan untuk mengetahui jarak respon dari Bluetooth smartphone pada bluetooth yang terpasang pada mesin. Adapun hasil dari pengujian yang dilakukan sebagai berikut.

\section{Tabel 1 Pengujian Sistem}

\begin{tabular}{|c|c|c|}
\hline No & Pengujian & Hasil Pengujian \\
\hline 1 & 1 Meter & Berhasil \\
\hline 2 & 2 Meter & Berhasil \\
\hline 3 & 4 Meter & Berhasil \\
\hline 4 & 5 Meter & Berhasil \\
\hline 5 & 6 Meter & Berhasil \\
\hline 6 & 7 Meter & Berhasil \\
\hline 7 & 8 Meter & Berhasil \\
\hline 8 & 10 Meter & Berhasil \\
\hline 9 & 12 Meter & Tidak berhasil \\
\hline 10 & 15 Meter & Tidak berhasil \\
\hline
\end{tabular}

Pengujian pada tabel 1 menunjukan sistem berfungsi dengan baik tanpa kendala dengan catatan masih dalam jarak efektif. Pengujian dilakukan 10 kali terhadap hardware dengan jarak 1-15 meter. Jarak efektif yang dapat dijangkau bluetooth adalah hingga 10 meter. Relay sebagai saklar pemutus dan penghubung antara kendaraan atau alat dan aplikasi. Dengan hasil tersebut maka kendaraan mampu atau bisa di kontrol secara otomatis tanpa harus menggunakan kunci motor secara konvensioanl lagi.

\section{KESIMPULAN}

Berdasarkan analisis, desain, implementasi perangkat lunak dan pembahasan pada bab-bab sebelumnya, maka dapat ditarik beberapa kesimpulan yaitu:

1) Menghubungkan smartphone dengan mikrokontroller arduino menggunakan metode voice recognition adalah dengan mengkoneksikan Antara Sistem atau Software dengan hardware.

2) Cara kerja sistem starter sepeda motor ini dengan cara mengontrol starter melalui smartphone android dengan voice recognition.

\section{DAFTAR PUSTAKA}

[1] Beman Suharjo, S. F. (2011). Perancangan Sistem Keamanan Sepeda Motor Dengan Sistem Sidik Jari. Jurnal Teknik Komputer, 17-27.

[2] Joyner R. Oroh, E. K. (2014). Rancang Bangun Sistem Keamanan Motor Dengan Pengenalan Sidik Jari. e-Journal Teknik Elektro dan Komputer , 1-7.

[3] Maya selvia, Hamdi Rahman. (2015). Implementasi Prototype Sistem Kendali Kunci Pintu Dengan Smartphone Android Berbasis Mikrokontroler. Prosisko, 3-7.

[4] Moh Ismin, Miftahul Walid. (2018). Perancangan Sistem Aplikasi Starter Sepeda Motor Menggunakan Arduino Berbasis Android. Sehati, 4-8. 
JEECOM, Vol. 2, No. 2, Oktober 2020

[5] Susanti, E. (2018). Perancangan Wireless Starter Kendaraan Bermotor Memanfaatkan Bluetooth Berbasis Arduino. Sigma Teknika, 12-15.

[6] Kholilah, I. (2016). Aplikasi Arduino Android Untuk sistem keamanan sepeda motor. Teknologi Rekayasa, 53-61.

[7] Khairul Agus Rizal, Naziruddin dan zamzani. (2016). Sistem Pengaman Barankas Menggunakan Kode Password Dan Sidik Jari Berbasis Sidik Jari. Jurnal Litek, 37-34.

[8] Herwanto, P. (2017). Pengaman Sepeda Motor Menggunakan Mikrokontroler Aeduino Uno Berbasis Android. Jurnal Informasi, 5-15.

[8] Tatik Juwariyah, Alina Cynthia Dewi. (2017). Rancang Bangun Sistem Keamanan Sepeda Motor Dengan Sensor Sidik Jari. Bina Teknika, 1-5. 